\title{
PERÍODOS DE INTERFERÊNCIA DE TRAPOERABA (Commelina benghalensis Hort.) NO CRESCIMENTO INICIAL DE EUCALIPTO (Eucalyptus grandis W. Hill ex Maiden) ${ }^{1}$
}

\author{
Augusto Guerreiro Fontoura Costa ${ }^{2}$, Pedro Luís da Costa Aguiar Alves ${ }^{3}$, Maria do Carmo Morelli \\ Damasceno Pavani ${ }^{3}$
}

\begin{abstract}
RESUMO - A trapoeraba (Commelina benghalensis), em razão do uso contínuo de mesmos herbicidas e outros métodos de controle, vem se constituindo numa das plantas mais freqüentes em eucaliptais do Estado de São Paulo. Por isso, objetivou-se neste trabalho avaliar os efeitos de períodos de controle e convivência dessa planta daninha sobre o desenvolvimento inicial de mudas de Eucalyptus grandis, transplantadas no inverno e no verão. Uma única muda de eucalipto foi transplantada em caixa de cimento-amianto e submetida a períodos crescentes de convivência e de controle da trapoeraba (0,20, 40,60 e 80 dias no sujo e no limpo, respectivamente), sendo a densidade de plantas de trapoeraba de 4 plantas. $\mathrm{m}^{-2}$ (nas condições de inverno e verão). Conduziuse o ensaio por um período de 100 dias após o transplante (DAT), e o delineamento experimental adotado foi o de blocos casualizados, com 10 tratamentos com quatro repetições. Pelos resultados da altura das plantas, diâmetro do caule, biomassa seca e área foliar, verificou-se que o período anterior à interferência (PAI), o total de prevenção à interferência (PTPI) e o período crítico de prevenção à interferência (PCPI) foram de 20, 60 e 20 a 60 DAT, respectivamente, no inverno. Em condições de verão, o PTPI foi menor que o PAI (10 e 40 DAT, respectivamente). Assim, não foi possível estabelecer o PCPI nessas condições.
\end{abstract}

Palavras-chave: Planta daninha, período crítico, controle.

\section{PERIODS OF Commelina benghalensis INTERFERENCE IN THE INITIAL GROWTH OF Eucalyptus grandis}

\begin{abstract}
Commelina benghalensis is becomming the predominant weed invading eucalypts plantations in the State of São Paulo due to the continual use of herbicides and other control methods applied. Considering this, the objective of this work was to evaluate the effect of presence and control periods of Commelina benghalensis on Eucalyptus grandis initial growth, grew in winter and summer. A single eucalypt seedling was planted in a cement box and submitted to increasing periods of presence and control of Commelina benghalensis $\left(0,20,40,60\right.$ e 80 days in competition or not). Commelina benghalensis plant density was 4 plants. $m^{-2}$ (in winner and summer conditions). The experimental period lasted for 100 days, after planting (DAP). The experimental design was arranged in a randomized block design (CRB) with 10 treatments and four replicates. The results for plant height, stem diameter, dry weights and leaf area showed that the period previous to interference (PPI), total period of interference control (TPIC) and critical period of interference control (CPIC), were 20, 60, and 20 to 60 DAP, respectively, in winner conditions. In summer conditions, TPIC was shorter than PPI (10 e 40 DAP, respectively), therefore it was not possible to determine CPIC in these conditions.
\end{abstract}

Key words: weed, critical period, control.

\footnotetext{
${ }^{1}$ Recebido para publicação em 24.4.2003 e aceito para publicação em 10.8.2004.

${ }^{2}$ UNESP - Rua Dr. José Barbosa de Barros, 1160, Ap. 24, Jardim Paraíso, CEP 18610-510 Botucatu, SP. E.mail: <augusto@fca.unesp.br>. ${ }_{3}^{3}$ Departamento de Biologia Aplicada à Agropecuária - F.C.A.V./UNESP. Via de acesso Prof. Paulo Donato Castellane, s/n, CEP 14884-900 Jaboticabal, SP.
} 


\section{INTRODUÇÃO}

A presença das plantas invasoras no ecossistema florestal tem sido um dos maiores problemas na implantação e manutenção das florestas de eucalipto e pinheiro, o que pode ser comprovado pelos estudos que apontam que a presença dessas plantas em reflorestamentos causa prejuízos ao crescimento e produtividade, uma vez que competem pela obtenção de luz, nutrientes, água e espaço e exercem pressão de natureza alelopática, além de aumentar riscos de incêndio e outros, justificando a preocupação com seu controle (PITELLI, 1987; PITELLI e MARCHI, 1991).

O termo interferência refere-se ao conjunto de ações que recebe determinada cultura ou atividade do homem, em decorrência da presença de plantas daninhas num ambiente (PITELLI, 1987).

Os fatores que afetam o grau de interferência entre plantas infestantes e culturas agrícolas estão apresentados em esquema proposto por Bleasdale (1960) e adaptado por Pitelli (1985). Segundo esse esquema, o grau de interferência depende de fatores ligados à própria cultura (espécie, espaçamento e densidade de plantio), à comunidade infestante (composição específica, densidade e distribuição), às condições específicas em que ocorre a associação cultura/comunidade infestante, principalmente condições edafoclimáticas e de tratos culturais; e, finalmente, depende também da época e extensão do período em que houve a associação.

Pitelli (1987) ponderou que, de maneira geral, quanto maior for o período de convivência múltipla, cultura/ comunidade infestante, maior será o grau de interferência. No entanto, isso não é totalmente válido, porque dependerá da época do ciclo da cultura em que tal período for concedido.

Segundo Pitelli e Marchi (1991), a interferência imposta por essas plantas é mais severa, principalmente, na fase inicial de crescimento do eucalipto, ou seja, do transplantio até cerca de um ano de idade. Para Kogan (1992), a pressão de competição que as plantas daninhas exercem em espécies perenes será logicamente maior em plantações recém-estabelecidas ou jovens.

Marchi (1987), estudando efeitos de períodos de controle de plantas daninhas no crescimento inicial e composição mineral de Eucalyptus grandis, no município de Guatapará, SP, observou que o período anterior à interferência (PAI) foi inferior a 28 dias e o período total de prevenção à interferência (PTPI), de 140 dias. A análise de custo/benefício revelou que a manutenção da cultura no limpo por um período de 112 dias proporcionou aceitável produção de madeira com menor custo.

Plantas jovens de Eucalyptus urograndis (Eucalyptus urophlla X Eucalyptus grandis) convivendo com Brachiaria decumbens apresentaram período anterior à interferência (PAI) inferior a 14-28 dias. Para garantir o desenvolvimento inicial da cultura, esta apresenta um período total de prevenção à interferência (PTPI) ao redor de 196 dias, sendo o período crítico de prevenção à interferência (PCPI) de 14-28 a 196 dias após o transplante (TOLEDO, 1998).

Durante alguns anos houve dificuldade no controle de Commelina benghalensis com os herbicidas existentes e, por isso, a invasora alastrou-se bastante. Além disso, é importante ressaltar que essa planta vem se tornando problemática nas áreas de reflorestamento no Estado de São Paulo, provavelmente como resultado de um processo de seleção promovido pelos métodos de controle e herbicidas utilizados.

A trapoeraba, em condições de inverno, interfere negativamente no crescimento das mudas deEucalyptus grandis já a partir de 4 plantas. $\mathrm{m}^{-2}$, principalmente na emissão de folhas e ramos, resultando em diminuição da massa seca (COSTA et al., 1998). Já em condições de verão, a partir da mesma densidade de plantas, interferiu, sobretudo, na produção de matéria seca de folhas e ramos. Além disso, passou a interferir também na altura e no diâmetro do caule das plantas de eucalipto (COSTA et al., 1997).

Baseando-se nos efeitos da densidade de trapoeraba observados por Costa et al. (1997; 1988), este trabalho procurou-se determinar os períodos de interferência desta planta daninha sobre o crescimento inicial de mudas de Eucalyptus grandis em condições de inverno e verão.

\section{MATERIAL E MÉTODOS}

Foram conduzidos dois ensaios sob condições semicontroladas (em condições de inverno e verão), nos quais se estudaram os efeitos de períodos de convivência e controle de Commelina benghalensis (trapoeraba) no crescimento inicial de mudas deEucalyptus 
grandis. As médias de temperatura (mínima e máxima) e a soma da precipitação durante a condução dos ensaios (100 dias) foram de 14,6;28,3; e 73,8 mm e 19,$8 ; 31,0 ;$ e $1154,8 \mathrm{~mm}$, nas condições de inverno e verão, respectivamente, de acordo com dados coletados na Estação Agroclimatológica da FCAV-UNESP, campus de Jaboticabal.

Os ensaios foram instalados em área experimental do Departamento de Biologia Aplicada à Agropecuária (FCAV - UNESP, campus de Jaboticabal). Como recipientes foram utilizadas caixas de cimento-amianto com capacidade para 70 litros, usando-se como substrato terra coletada na camada arável de um Latossolo Vermelho distrófico, de classe textural argilosa. $\mathrm{O}$ substrato foi previamente corrigido, quanto à fertilidade, com adubo formulado 04-14-08 e com adubação complementar de cobertura com sulfato de amônia.

Uma única muda de eucalipto com aproximadamente 90 dias de idade foi plantada em cada recipiente. Em cada época correspondente ao tratamento (período de convivência ou controle), as plântulas de trapoeraba, no estágio de duas a quatro folhas, foram transplantadas no recipiente, na densidade de 4 plantas. $\mathrm{m}^{-2}$, nas condições de verão e inverno. A densidade de $C$. benghalensis foi essa mesma do eucalipto, conforme recomendação de Costa et al. (1997; 1998).

Os tratamentos experimentais foram divididos em dois grupos. O primeiro constou de períodos crescentes de convivência das plantas de eucalipto com a trapoeraba desde o transplantio até $0,20,40,60$ e 80 dias depois. Ao final de cada período, toda a população da planta daninha foi eliminada. No segundo grupo de tratamentos, as plantas de eucalipto permaneceram na ausência das de trapoeraba (no limpo) desde o transplantio até $0,20,40,60$ e 80 dias após. Ao final desses períodos de ausência (controle), as mudas das plantas daninhas foram transplantadas. O período de condução dos ensaios foi de 100 dias após o transplantio do eucalipto, período em que as plantas cresceram sem limitação de água.

O delineamento experimental adotado nos dois ensaios foi o de blocos casualizados, com 10 tratamentos em quatro repetições.

As avaliações das espécies foram as seguintes:

a) Eucalipto: aos 30, 50 e 100 dias após o trans- plantio das mudas (DAT), foram medidos a altura das plantas e o diâmetro do caule, sendo este último obtido por medições na região do colo e a altura das plantas, pelo comprimento do caule principal. Ao término do período experimental (100 DAT), avaliaram-se o número de folhas e ramos, a área foliar e o peso de matéria seca das folhas, caule e ramos de todas as plantas.

A área foliar foi obtida por meio de um medidor de área foliar (Li-Cor Instruments, modelo LI-3000A) e a matéria seca das diferentes partes das plantas, após a secagem do material em estufa com circulação forçada de ar, a $70^{\circ} \mathrm{C}$, por 96 horas, que foi posteriormente pesado em balança de precisão de $0,01 \mathrm{~g}$.

b) Trapoeraba: ao término dos respectivos períodos de convivência e aos $100 \mathrm{DAT}$ (para os períodos de controle) foi avaliada a biomassa seca da parte aérea das plantas infestantes.

Os dados foram expressos pelas suas médias, sendo estas submetidas às análises de regressão, segundo os modelos de Boltzman $\left(\mathrm{Y}=\left[\left(\mathrm{A}_{1}-\mathrm{A}_{2}\right) /\left(1+\mathrm{e}^{\mathrm{X}-\mathrm{X} 0 / \mathrm{dX}}\right)+\mathrm{A}_{2}\right]\right)$, e de regressão exponencial $\left(\mathrm{Y}=\mathrm{Y}_{0}+\mathrm{A} \cdot \mathrm{e}^{-(\mathrm{X}-\mathrm{X} 0 / \mathrm{T})}\right)$ do programa Microcal Origin, versão 3.0.

\section{RESULTADOS E DISCUSSÃO}

\section{a) Ensaio em condições de inverno}

Pode-se observar, na Figura 1, que o peso da matéria seca da parte aérea das plantas de trapoeraba foi crescente dos 0 aos 80 dias de convivência e decrescente dos 0 aos 80 dias de ausência da planta daninha. A ascendência e o declínio das curvas ocorreram aos 80 dias no limpo e 40 dias no sujo, respectivamente.

Quanto à altura das plantas de eucalipto (Figura 2 A), constatou-se, aos 100 DAT, que a partir dos 40 dias no limpo as plantas de eucalipto apresentaram tendência de serem maiores do que as do período de 0 dia de controle (presença de planta daninha) (21\%); após o qual essa tendência se estabilizou. Pode-se verificar, nessa figura, que o comportamento praticamente inverso (redução de altura) e em período análogo (40 dias com presença de trapoeraba) ocorreu nos períodos de convivência, com $22 \%$ de diminuição em relação a 0 dia sem manejo de planta daninha. Entretanto, Costa et al. (1998) observaram que até os 90 dias de convivência, entre essas duas espécies, com a infestante na densidade de 4 plantas. $\mathrm{m}^{-2}$ e em condições de inverno, não houve efeito sobre a altura das plantas de Eucalyptus grandis. 


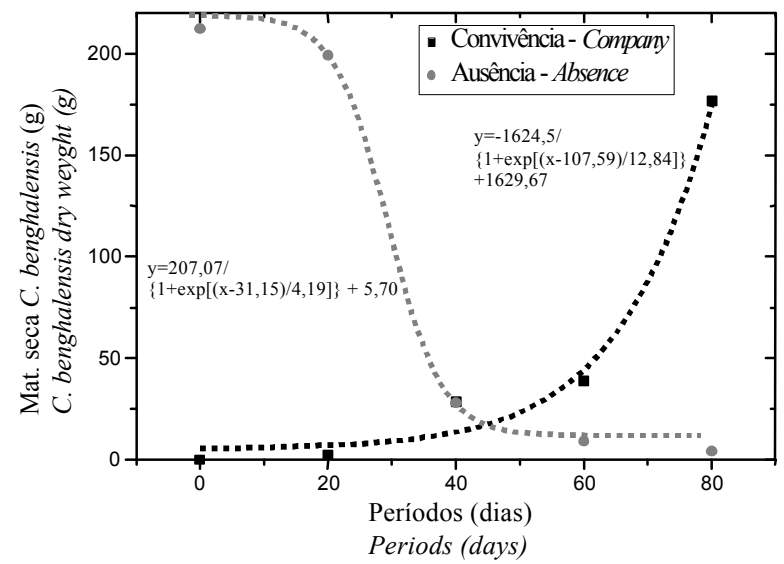

Figura 1 - Biomassa seca acumulada da parte aérea deCommelina benghalensis, aos 100 DAT, em função dos períodos de interferência, em condições de inverno.

Figure 1-Dry matter accumulated from aerial part of Commelina benghalensis $100 \mathrm{DAP}$, in function of interference periods, in the winter.

Aos 100 DAT, os períodos de controle resultaram uma curva do diâmetro do caule que foi muito semelhante ao ocorrido com a altura das plantas de eucalipto, ou seja, crescente do 0 aos 40 dias no limpo e estabilização na seqüência, com acréscimo de $27 \%$. Nos períodos de convivência, a curva foi decrescente dos 0 aos 20 dias com presença de trapoeraba, com redução de $25 \%$ no diâmetro do caule a partir deste período, após o qual a diminuição tendeu a se estabilizar (Figura 2B).

Com relação a esses dois parâmetros (diâmetro do caule e altura), o período de controle da trapoeraba mostrou-se eficiente a partir dos 40 dias, evitando as reduções quando em convivência.

A área foliar das plantas de eucalipto (Figura 3A) foi diminuída, de modo acentuado, aos 60 dias com a presença de trapoeraba ( $45 \%$ em relação a 0 dia), chegando a uma redução de $78 \%$ aos 80 dias de convivência.

Esse resultado está relacionado à diminuição de $33 \%$ no número de folhas a partir dos 20 dias de convivência. O número de ramos apresentou uma curva decrescente menos drástica, havendo redução mais visível a partir dos 80 dias (30\%). Tais efeitos deletérios tenderam a aumentar com os dias de convivência, o que pode ser observado na Figura $2 \mathrm{C}$ e D.

R. Árvore, Viçosa-MG, v.28, n.4, p.471- 478, 2004
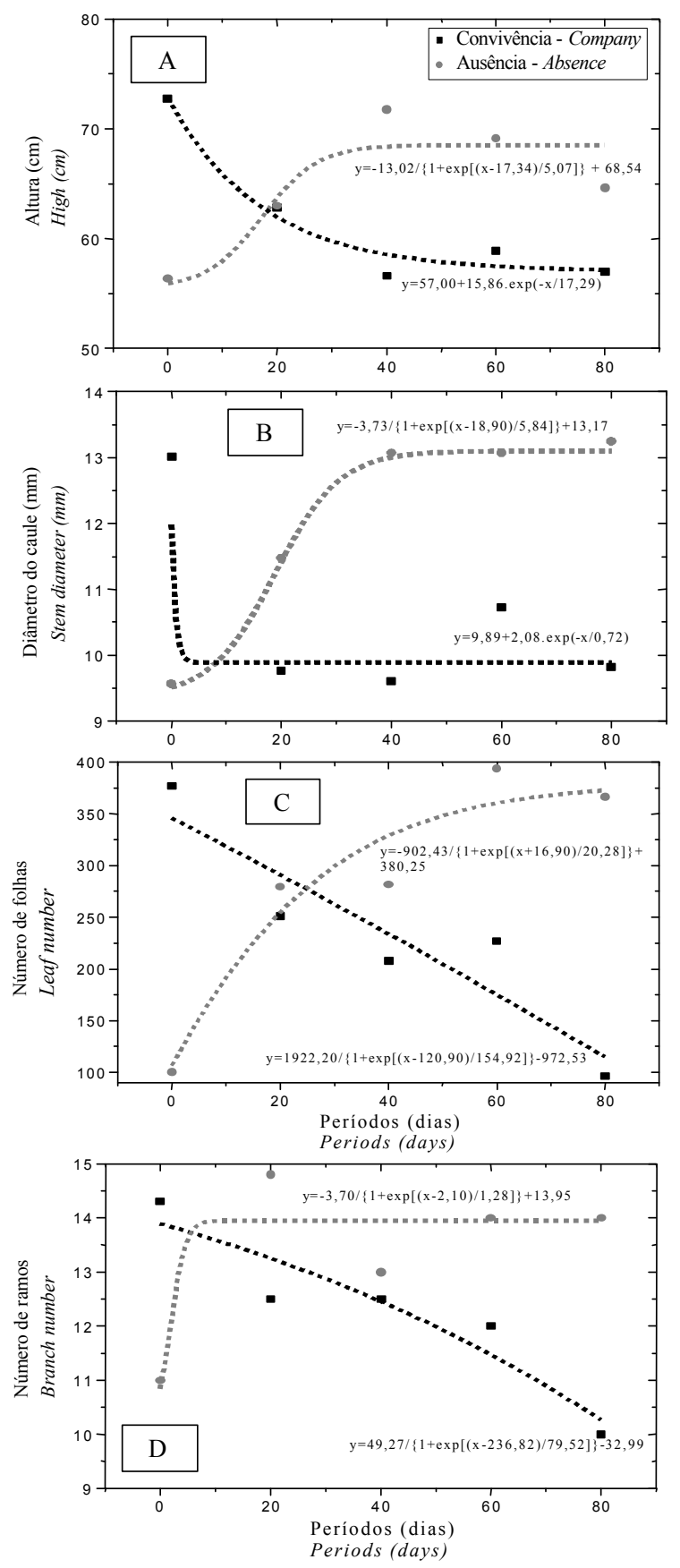

Figura 2 - Efeitos dos períodos de interferência sobre altura (A), diâmetro do caule (B) e número de folhas (C) e ramos (D) das plantas deEucalyptus grandis aos 100 DAT, em condições de inverno.

Figure 2 - Effects of interference periods on height (A), stem diameter $(B)$, leaf $(C)$ and branch number $(D)$ of Eucalyptus grandis $100 \mathrm{DAP}$, in winter. 

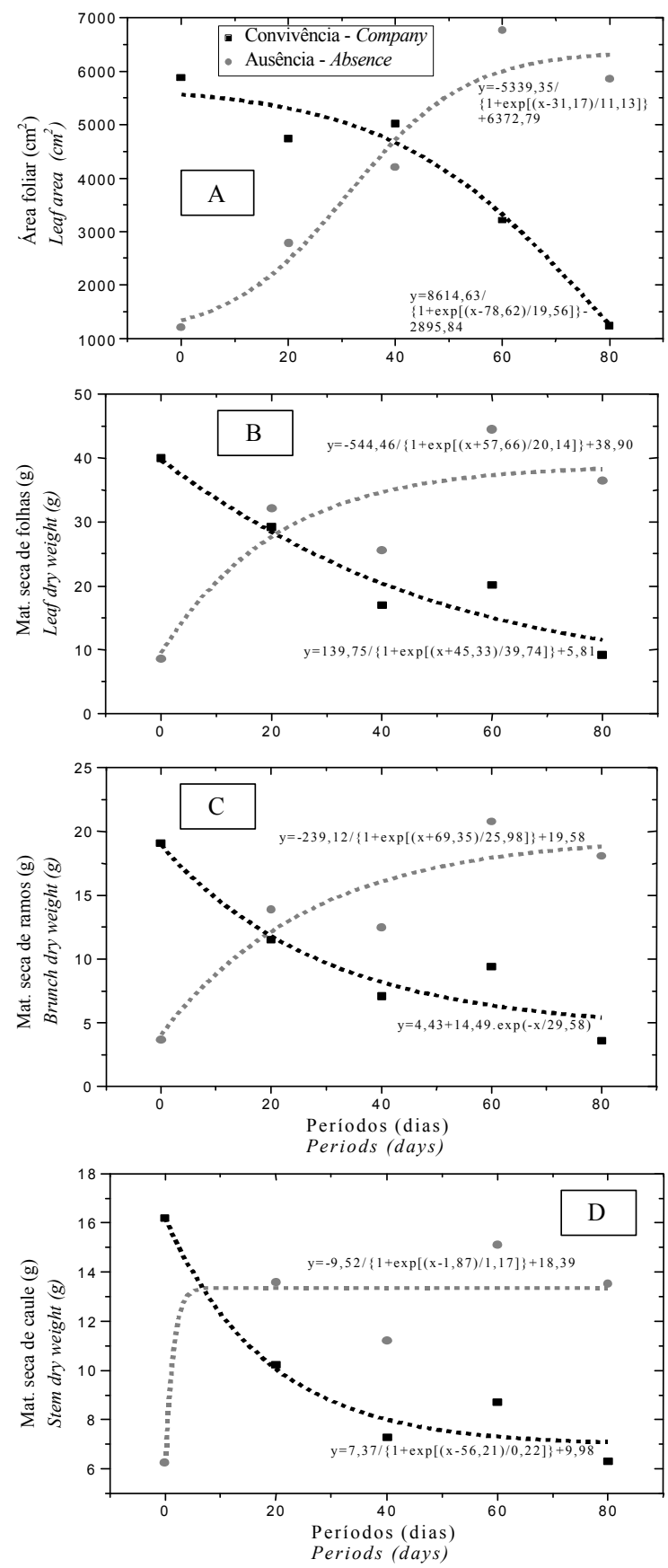

Figura 3 - Efeitos dos períodos de interferência sobre área foliar (A), matéria seca de folhas (B), $\operatorname{ramos}(\mathrm{C})$ e caule (D) das plantas de Eucalyptus grandis aos 100 DAT, em condições de inverno.

Figure 3 -Effects of interference periods on leaf area $(A)$, leaf $(B)$, branch $(C)$ and stem $(D)$ dry matter of Eucalyptus grandis $100 \mathrm{DAP}$, in winter.
Segundo Costa et al. (1998), a redução na área foliar (26\%) de E. grandis, que conviveu durante 90 dias com plantas de C. benghalensis (4 plantas. $\mathrm{m}^{-2}$ ), em condições de inverno, pode ser atribuída, principalmente, à diminuição no número de folhas e ramos (21 e 17\%, respectivamente).

Na Figura 3A, observa-se, também, que a área foliar foi crescente em resposta ao aumento nos dias de controle já a partir dos 20 dias ( $57 \%$ de acréscimo comparado a 0 dia), chegando, aos 40 dias, a ser $71 \%$ maior em relação a 0 dia sem a presença de trapoeraba. No que diz respeito a essa característica, a curva tendeu a se estabilizar a partir dos 60 dias de controle. A curva crescente do número de folhas, a partir dos 20 dias de controle (acréscimo de $39 \%$ em relação a 0 dia no limpo), talvez explique o ocorrido na área foliar, tendendo a se estabilizar também aos 60 dias. A característica do número de ramos das plantas de eucalipto mostrou-se menos sensível ao período de controle, ressaltando-se que a curva estabilizou-se após os 20 dias de controle e apresentou acréscimo de 14\% nesse período em relação a 0 dia no limpo.

Observou-se que na biomassa seca dos ramos de eucalipto houve acréscimo até os 60 dias de controle, após o qual tendeu a se estabilizar; aos 20 dias, o acréscimo foi de $73 \%$ em relação a todo o período com competição da trapoeraba - 0 dia no sujo (Figura 3C). Comportamento semelhante foi observado na curva de biomassa seca de folhas, sendo o mesmo acréscimo percentual nos 20 dias de controle (Figura 3B). Na matéria seca do caule, a curva estabilizou-se de forma drástica após os 20 dias de controle, implicando 54\% de acréscimo nesse período (Figura 3D).

Nos períodos de convivência, aos 20 dias a matéria seca de ramos foi menor $45 \%$ em relação ao tratamento sem competição durante todo o ciclo, com o decréscimo acentuando-se até 40 dias no sujo. Fato semelhante pode ser observado nos gráficos que representam os dados obtidos de biomassa seca de folhas e caule ( 37 e $25 \%$ de decréscimo, respectivamente, aos 20 dias no sujo). Entretanto, Costa et al. (1998) constataram reduções menores dessas características em condições de inverno, sendo as mesmas espécies em convivência, aos 90 dias, com a infestante na mesma densidade. Tais reduções foram de 39, 28 e $19 \%$ de biomassa seca de ramos, folhas e caule, respectivamente.

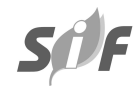

R. Árvore, Viçosa-MG, v.28, n.4, p.471- 478, 2004 
Pode-se constatar que o período de convivência passou a ser crítico quando a planta de trapoeraba acumulou cerca de $29 \mathrm{~g}$ de biomassa seca (40 dias no sujo) e, no período de controle, quando tais plantas acumularam por volta de $200 \mathrm{~g}$ (20 dias no limpo).

\section{b) Ensaio em condições de verão}

Pode-se observar, na Figura 4, que a biomassa seca das plantas de trapoeraba foi crescente a partir dos 40 dias de ausência de trapoeraba e decrescente, de forma acentuada, entre 20 e 60 dias de convivência, em que ambas as curvas tenderam a se estabilizar após os 60 dias.

Aos 100 dias, observa-se na Figura 5 A que, quanto à altura das plantas de eucalipto, houve decréscimo da curva após 40 dias de convivência, indicando uma tendência de redução de $12 \%$ aos 60 dias, em relação a 0 dia no sujo. Costa et al. (1997) também observaram reduções nessa característica em plantas de $E$. grandis que conviveram com $C$. benghalensis, aos 30, 60 e 90 dias, na mesma densidade da infestante e em condições de verão.

Com relação ao diâmetro do caule, a curva apresentou decréscimo no mesmo intervalo (40 a 60 dias), o que em termos numéricos, no entanto, não representa tendência de diminuição, em comparação a 0 dia no sujo (Figura 5 B).

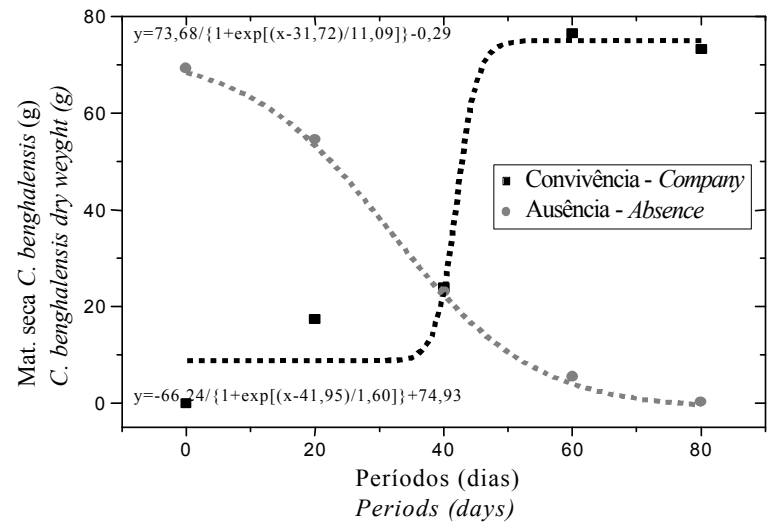

Figura 4 - Biomassa seca acumulada da parte aérea deCommelina benghalensis aos $100 \mathrm{DAT}$, em função dos períodos de interferência, em condições de verão.

Figure 4-Dry matter accumulated from aerial part of Commelina benghalensis $100 \mathrm{DAP}$, in function of interference periods, in the summer.

R. Árvore, Viçosa-MG, v.28, n.4, p.471- 478, 2004
Com relação aos períodos de controle, as plantas foram 14\% mais altas aos 20 dias, em comparação a 0 dia no limpo, estabilizando-se após. Quanto ao diâmetro do caule, não foi constatado efeito algum dos dias de controle.

Observa-se, na Figura 6A, que a curva correspondente à área foliar foi crescente até os 20 dias de controle ( $32 \%$ de acréscimo) - após o que se estabilizou - o mesmo ocorrendo no número de folhas, com 30\% de acréscimo no mesmo período (Figura 5C). Entretanto, com relação a número de ramos, não foi observado efeito dos períodos de controle (Figura 5D).

Os períodos de convivência de 40 e 60 dias com competição promoveram decréscimo de área foliar, após o que se estabilizou, sendo a redução de $42 \%$ aos 60 dias. Apesar de as curvas serem decrescentes quanto ao número de ramos e folhas, as reduções foram insignificantes.

Em biomassa seca de folhas, ramos e caule (Figura 6 B C D, respectivamente), os períodos de controle implicaram curvas crescentes do 0 aos 20 dias no limpo, com diferenças de 49, 60 e 50\% entre esses dois períodos, respectivamente, estabilizando-se após.

Nos períodos de convivência, as biomassas secas de caule e ramos das plantas de eucalipto implicaram decréscimo da curva, também entre os 40 e 60 dias, resultando em reduções de 27 e $33 \%$, respectivamente. Com relação à biomassa seca de folhas, apesar de a curva ter decrescido, as reduções foram muito baixas. Quanto a essas mesmas características, Costa et al. (1997) observaram diminuições de 23, 39 e 29\% nas biomassas secas de caule, ramos e folhas, respectivamente, aos 90 dias de convivência com $C$. benghalensis ( 4 plantas. $\mathrm{m}^{-2}$ ), em condições de verão.

Pôde-se constatar que o período de convivência passou a ser mais crítico quando a planta de trapoeraba acumulou cerca de $77 \mathrm{~g}$ de biomassa seca $(60$ dias no sujo), assim como o período de controle, quando tais plantas acumularam cerca de $55 \mathrm{~g}$ de matéria seca em sua parte aérea (20 dias no limpo).

Nas duas condições dos ensaios (inverno e verão) foi possível observar que, quanto maiores foram os períodos de convivência, maiores foram as diminuições das características estudadas das plantas de eucalipto. Tal constatação é corroborada por Pitelli (1987), que afirmou ser maior o grau de interferência quanto maior for o período de convivência múltipla cultura/comunidade infestante. 

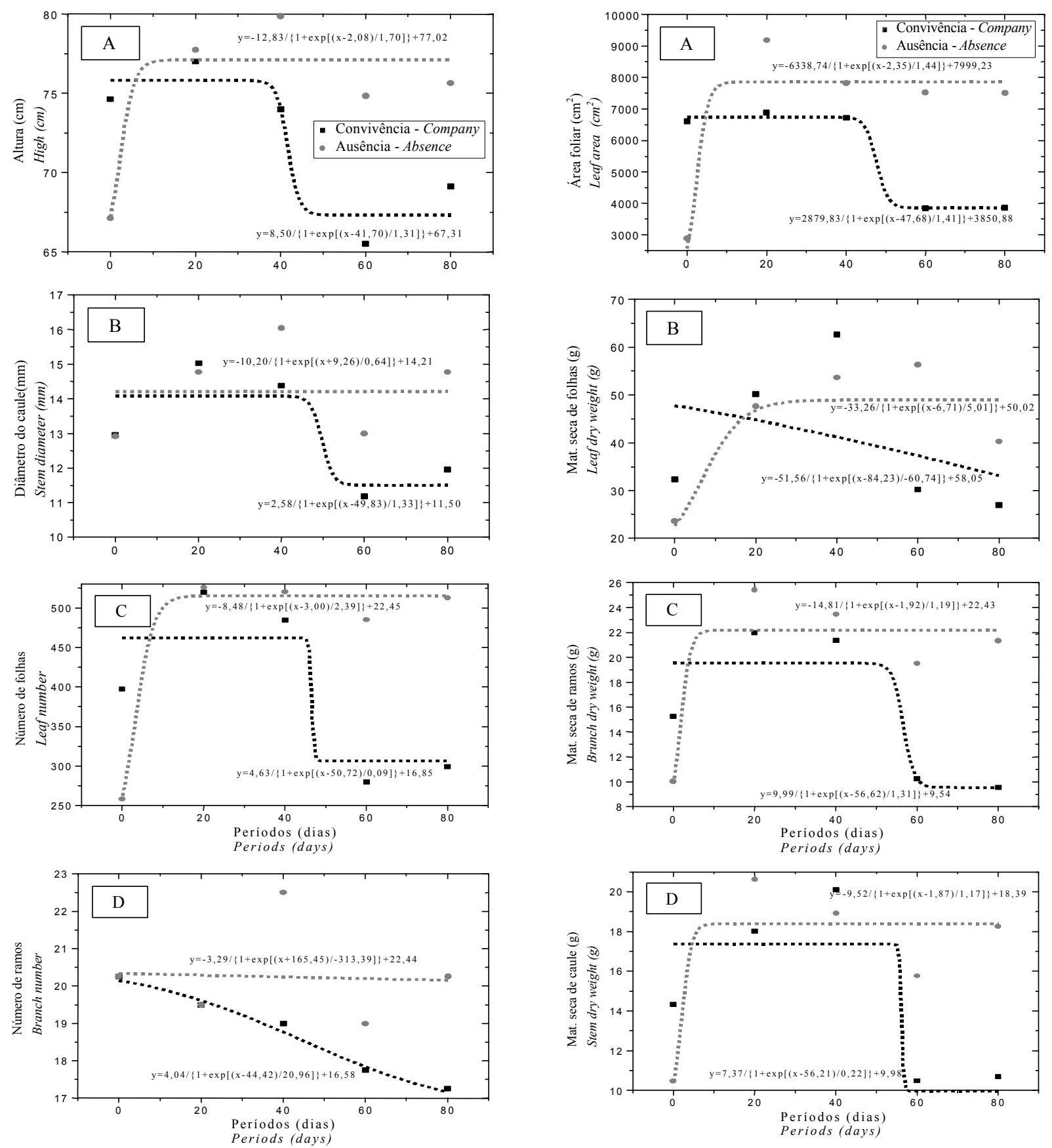

Figura 5 - Efeitos dos períodos de interferência sobre altura (A), diâmetro do caule (B) e número de folhas (C) e ramos (D) das plantas de Eucalyptus grandis aos 100 DAT, em condições de verão.

Figure 5 - Effects of interference periods on height (A), stem diameter $(B)$, leaf $(C)$ and branch number $(D)$ of Eucalyptus grandis $100 \mathrm{DAP}$, in the summer.

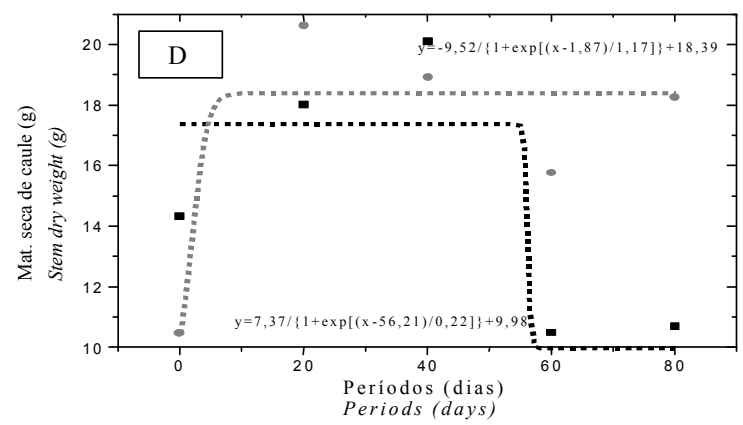

Figura 6 - Efeitos dos períodos de interferência sobre área foliar (A), matéria seca de folhas (B), ramos (C) e caule (D) das plantas de Eucalyptus grandis aos 100 DAT, em condições de verão.

Figure 6 -Effects of interference periods on leaf area $(A)$, leaf $(B)$, branch $(C)$ and stem $(D)$ dry weight of Eucalyptus grandis $100 \mathrm{DAP}$, in the summer. 


\section{CONCLUSÃO}

A C. benghalensis na densidade de 4 plantas. $\mathrm{m}^{-2}$ em condições de inverno e a partir dos 40 dias de convivência, com plantas de $E$. grandis, reduziu a área foliar, o número de folhas e as biomassas secas de ramos e folhas. Em termos de controle, a partir dos 20 dias os efeitos deletérios foram diminuídos na área foliar e na produção das biomassas secas de ramos, caule e folhas das plantas de eucalipto.

Em condições de inverno, período anterior à interferência (PAI), total de prevenção à interferência (PTPI) e período crítico de prevenção à interferência (PCPI) foram de 20, 60 e 20 a 60 DAT, respectivamente.

A C. benghalensis na densidade de 4 plantas. $\mathrm{m}^{-2}$ em condições de verão e a partir dos 60 dias de convivência reduziu, principalmente, a área foliar. Em termos de controle, a partir dos 20 dias os efeitos deletérios foram diminuídos principalmente na produção de biomassas secas de ramos, caule e folhas das plantas de eucalipto.

Em condições de verão, o PTPI foi menor que o PAI (10 e 40 DAT, respectivamente), não sendo, assim, possível estabelecer o PCPI nessas condições.

\section{AGRADECIMENTOS}

Ao CNPq, à FCAV/UNESP-Jaboticabal e à VCP (unidade de Luiz Antônio,SP).

\section{REFERÊNCIAS BIBLIOGRÁFICAS}

BLEASDALE, J.K.A. Studies on plant competition. In: HARPER, J.L. The biology of Weeds. Oxford: Blackwell Scientific Publication, 1960. p.133-43.

COSTA, A.G.F.; PAVANI, M. C.M.D.; ALVES, P.L. C.A. Interferência de Commelina benghalensis, em densidades crescentes, no desenvolvimento inicial de mudas de Eucalyptus grandis In: CONGRESSO DE INICIAÇÃO CIENTÍFICADA UNESP, 9. 1997, Jaboticabal. Anais... Jaboticabal: Universidade Estadual de São Paulo, 1997. p.295.
COSTA, A.G.F.; PAVANI, M. C.M.D.; ALVES, P.L. C.A. Interferência de Commelina benghalensis, em densidades crescentes, no desenvolvimento inicial de mudas de Eucalyptus grandis, em condições de inverno In: REUNIÃO ANUAL DA SBPC, 50., 1998, Natal. Anais... Natal: SBPC, 1998. p.52.

KOGAN, M.A. Interferencia de las malezas en plantaciones forestales y estratégias de control. In: Avances em Manejo de Malezas en Producion Agricola y Forestal. Santiago: Pontificia Universidad Catolica, 1992. p.119.

MARCHI, S.R. Efeitos de períodos de controle das plantas daninhas no crescimento inicial e composição mineral de Eucalyptus grandis Hill ex Maiden. 1987. 98 f. Dissertação (Graduação em Agronomia) - Universidade Estadual de São Paulo, Jaboticabal, 1987.

PITELLI, R.A. Interferência de plantas daninhas em culturas agrícolas. Informe

Agropecuário, v.11, n.129, p.16-27, 1985.

PITELLI, R.A. Competição e controle de plantas daninhas em áreas agrícolas. IPEF, v.4, n.12, p.25-35, 1987.

PITELLI, R.A.; MARCHI, S.R. Interferência das plantas invasoras nas áreas de reflorestamento. In: SEMINÁRIO TÉCNICO SOBRE PLANTAS DANINHAS E O USO DE HERBICIDAS EM REFLORESTAMENTO, 1., 1991, Rio de Janeiro. Anais... Rio de Janeiro: 1991. p.110-23.

TOLEDO, R.E.B. Efeitos da faixa de controle e dos períodos de controle e de convivência de Brachiaria decumbens Stapf. no desenvolvimento inicial de plantas de Eucalyptus urograndis. 1998. 77 f. Dissertação (Mestrado em Agronomia) - Escola Superior de Agricultura Luiz de Queiroz, 1998. 